\title{
The physical properties of the addition of reinforcement metals of Aluminum and silica microparticles with unsaturated composite materials
}

\author{
Najah Rustum Mohsin ${ }^{1}$, Ahmed Sahib Mahdi ${ }^{2}$, Ayad abdul ameer abdul hussein ${ }^{3}$, Mohammad \\ Sukri Mustapa ${ }^{4}$ \\ \{najahr2000@stu.edu.iq ${ }^{1}$, ahmed.altaei@stu.edu.iq ${ }^{2}$, Ayad.abdulameer@stu.edu.iq ${ }^{3}$, \\ sukri@uthm.edu.my ${ }^{4}$ \} \\ Southern Technical University (STU), Iraq ${ }^{1,2,3}$ \\ Universiti Tun Hussein Onn Malaysia (UTHM) ${ }^{4}$
}

\begin{abstract}
The absorption has a destructive effect on the mechanical and physical characteristics of the composite materials with a polymer base. It causes a reduction in the mechanical property values due to slight bonds between the matrix and the fibers. In the current paper, unsaturated polyester (UP) composite immersed in water, acidic solution $(\mathrm{HCl})$, and the alkaline solution $(\mathrm{KOH})$ were studied to investigate the effect of reinforcement on the thermal conductivity and absorption percentage values. Aluminum, Silica dioxide microparticles $\left(\mathrm{SiO}_{2}\right)$, and glass fibers $(\mathrm{GF})$ were adopted as reinforcing materials. Three types of composite material were prepared: (C1) UP only, (C2) UP reinforced with $15 \%$ aluminum particles and $15 \%$ GF, and (C3) UP reinforced with $15 \%$ aluminum particles and $15 \% \mathrm{SiO}_{2}$. The empirical results displayed that, large values of thermal conductivity were obtained with the specimen $\mathrm{C} 2$ composite, and it reduced when the immersion time increased. On the other hand, when immersed in water, acid or alkaline solutions, the absorption of the non-reinforced composite was less than that of the reinforced composite, but with increasing the period of immersion it is noticed that the absorbance value increases for the non-reinforced composite while it decreases for the reinforced composite.
\end{abstract}

Keywords: Aluminum particles, Silica dioxide Unsaturated polyester, Glass fiber, Absorption, Immersion.

\section{Introduction}

Composite materials are characterized by their lightweight, high resistance, and flexibility in design, which made them play an important role in all engineering applications such as building aircraft, satellites, spacecraft, etc. Composite materials consist of polymers, plastic material, or light resins such as epoxy as a base material (matrix) immersed in its high strength fibers (synthetic fibers or natural fibers) such as Kevlar, glass, jute, sisal, etc. Where the matrix material works to transfer and distribute applied forces and stresses between the fibers, as well as working to collect and preserve those fibers from any harmful external Things. Fibers can be designed according to the load's direction; this will lead to weight reduction with the optimum use of materials. In recent years, a major importance to use the reinforcement of natural fibers in composite materials due to their superior properties such as density, low cost, corrosion 
resistance, the biodegradability of non-toxic materials, and other unique characteristics [1,2,3]. George et.al.[4] elaborated the effect of some parameters of flax fiber on the epoxy composites intended by the autoclave molding method. H. Rashed et.al. [5] 2006 used jute fibers with different lengths and weight ratios to reinforce the polypropylene. P. N. Khanam [6] improved tensile and flexure strength by reinforcing unsaturated polyester by adding carbon and sisal fibers. M. R. Ismail et.al. [7] Used straw fibers as reinforcement, they obtained modulus of elasticity, impact strength, and flexural strength will be progressed with the rising of polymer ratio, while the water absorption is reduced with rising the polystyrene content in the same installation. V. Mittal et.al. [10] reinforced the epoxy with bagasse fibers and wheat straw fibers in different weight ratios and studied the influence of this on thermal, mechanical, and absorption properties.

In the current paper, unsaturated polyester resin (UP) was reinforced with Aluminum particles, glass fibers (GF), and silica dioxide $\left(\mathrm{SiO}_{2}\right)$ particles. For those samples, the influence of immersing duration of the water, acid solution $(\mathrm{HCl})$, and the alkaline solution $(\mathrm{KOH})$ on the thermal conductivity and absorption percentage were investigated.

\section{EXPERIMENTAL WORK}

\subsection{Material used}

\subsubsection{Aluminum particles}

Aluminum particles are used in a variety of applications in the industry, such as Cement, solid fuel, paint, and another coating. Aluminum is characterized by its lightweight and its high resistance to external stresses, good surface area, high hardness compares with polymer. Particle size (50-100) $\mu \mathrm{m}$ was used in this paper. The density of aluminum is $2.7{\mathrm{~g} \backslash \mathrm{cm}^{3}}_{\text {[14] }}$.

\subsubsection{Silica particles}

Silica particles have good resistance to acid and alkaline solutions, good surface area, high hardness, reduces thermal expansion of the polymer, and are cheap. Micro-silica particles with (50-100) $\mu \mathrm{m}$ size and density are $2.2 \mathrm{~g} / \mathrm{cm} 3$ from BASF Company were used in this paper [15].

\subsubsection{Glass fibers}

Glass fibers (type E-glass) with properties reported in Table 1 were used as reinforced material.

Table 1: Mechanical Properties of E-glass fibers [12].

\begin{tabular}{cccc}
\hline $\begin{array}{c}\text { Tensile } \\
\text { strength } \\
\mathrm{MPa}\end{array}$ & $\begin{array}{c}\text { Modulus of } \\
\text { elasticity } \\
\mathrm{GPa}\end{array}$ & $\begin{array}{c}\text { Density } \\
\mathrm{g} \backslash \mathrm{cm}^{3}\end{array}$ & $\begin{array}{c}\text { Poison's } \\
\text { ratio }\end{array}$ \\
\hline 3450 & 72.4 & 2.54 & 0.2 \\
\hline
\end{tabular}




\subsubsection{Unsaturated polyester}

The unsaturated polyester resin is widely used in the industry because it has good physical and mechanical properties as well as ease of use and low cost. It is a transparent, viscous liquid and thermosetting resin, which is characterized by its high efficiency and low in both density and viscosity. In the current research, the unsaturated polyester resin was used as a polymer matrix. Methyl-ethyl-ketone peroxide with mixing ratios of $2 \%$ was used as a catalyst (hardener material). Both are manufactured by Industrial Chemicals \& Resins Co. Ltd. Some properties of this resin are presented in Table 2.

Table 2: properties of unsaturated polyester resin [11, 12].

\begin{tabular}{cccccccc}
\hline $\begin{array}{c}\text { Tensile } \\
\text { strength } \\
\mathrm{MPa}\end{array}$ & $\begin{array}{c}\text { Modulus } \\
\text { of } \\
\text { elasticity } \\
\mathrm{GPa}\end{array}$ & $\begin{array}{c}\text { Density } \\
\mathrm{g} \backslash \mathrm{cm}^{3}\end{array}$ & $\begin{array}{c}\text { Elon. } \\
\%\end{array}$ & $\begin{array}{c}\text { Fracture } \\
\text { toughness } \\
\mathrm{MPa}-\mathrm{m}^{0.5}\end{array}$ & $\begin{array}{c}\text { Thermal } \\
\text { conductivity } \\
\mathrm{w} / \mathrm{m} \cdot \mathrm{k}\end{array}$ & $\begin{array}{c}\text { Poison's } \\
\text { ratio }\end{array}$ & $\begin{array}{c}\text { Thermal } \\
\text { expansion } \\
\text { coeff. } \\
10-6 / \mathrm{c}^{\circ}\end{array}$ \\
\hline $34.5-103$ & $2.1-3.4$ & $1.1-1.4$ & 2.6 & 0.6 & 0.17 & $0.37-0.4$ & $100-180$ \\
\hline
\end{tabular}

\subsection{Sample Preparation}

Since it is simple, easy, and cheap, the proceeding of Hand Lay-up (HLU) was used to prepare the samples. Glass mold with dimensions $(250 \times 250 \times 6) \mathrm{mm}$ were used with wax to avoid sticking to it and having smooth faces. The volume fractions were calculated according to the relations:

$V_{r}=\frac{M_{r}}{M_{r}+\left(1-M_{r}\right) \frac{\rho_{r}}{\rho_{m}}}$

$V_{m}=\frac{M_{m}}{M_{m}+\left(1-M_{m}\right) \frac{\rho_{m}}{\rho_{r}}}$

$V_{r}+V_{m}=1$

Where $\mathrm{V}, \mathrm{M}, \rho, \mathrm{m}$, and $\mathrm{r}$ represent volume fraction, mass, density, matrix, and reinforcement respectively. The specimens were cut into standard dimensions according to American specifications (ASTM-D 790-1984). The abbreviations and designation used in this study to address the different composite specimens are presented in Table 3.

Table 3: Abbreviations and details of the specimens Content.

\begin{tabular}{cccc}
\hline Abbreviation & Description & Total Vr\% & Total Vm\% \\
\hline $\mathrm{C} 1$ & $\begin{array}{c}\text { Pure unsaturated } \\
\text { polyester resin }\end{array}$ & 0 & 100 \\
\hline $\mathrm{C} 2$ & $\begin{array}{c}15 \% \mathrm{Al}+15 \% \mathrm{GF}+ \\
70 \% \mathrm{UP}\end{array}$ & 30 & 70 \\
\hline $\mathrm{C} 3$ & $\begin{array}{c}15 \% \mathrm{Al}+15 \% \text { Micro } \mathrm{SiO}_{2} \\
+70 \% \mathrm{UP}\end{array}$ & 30 & 70 \\
\hline
\end{tabular}




\subsection{Samples immersion in the solutions}

Three types of solutions were used, which were tap water, hydrochloric acid ( $\mathrm{HCl}$ ) (Acidic solution), and potassium hydroxide $(\mathrm{KOH})$ (Alkaline solution) with the normality of $(1 \mathrm{~N})$. The samples were weighed at room temperature by a sensitive balance with an accuracy of 0.0001 .

\subsection{Specimens absorption}

Absorption is defined as the penetration of a liquid into a solid during a certain period. The absorption percentage (Weight gain percentage) can be extracted from the following relationship [10]:

$$
\mathrm{M} \%=\frac{\left(M_{2}-M_{1}\right)}{M_{2}} \times 100 \%
$$

Where: $M \%$ : is the absorption percentage, $\mathrm{M}_{1}$ and $\mathrm{M}_{2}$ : is the weight before and after immersion in solution respectively.

\subsection{Thermal conductivity of specimens}

Thermal conductivity represents the measurement of heat flow per unit time out of a unit area of a substance. It can be measured in several ways, in this paper; Lee's disc (made by Griffen and George) was used to study the effect of immersion time in the water on the value of thermal conductivity. Ideally, thermal conductivity is governed by Fourier's Law of thermal conductivity shown in the following related:

$q=-K \frac{d T}{d x}$

Where: q: Thermal flux, K: thermal conductivity coefficient, dT / dx: thermal gradient When using Lee's disc, Thermal conductivity values can be extracted from the following two equations [16]:

$K\left[\frac{T_{B-} T_{A}}{d s}\right]=e\left[T_{A}+\frac{2}{r}\left[d_{A}+\frac{1}{4} d_{A}\right] T_{A}+\frac{1}{2 r} d_{S} T_{B}\right]$

Where: (DA, DB, DC): represent to a thickness of disks A, B, and C, respectively, $\left(\mathrm{T}_{\mathrm{A}}, \mathrm{T}_{\mathrm{B}}, \mathrm{T}_{\mathrm{C}}\right)$ : temperatures of $\mathrm{A}, \mathrm{B}$, and $\mathrm{C}$ disks, respectively, $\mathrm{r}$ : disk radius and e refer to the amount of thermal energy that passes through the disk per second and can be calculated by using the equation:

$$
e\left[d_{A} T_{A}+d s\left(\frac{T_{A}+T_{B}}{2}\right)+d_{B} T_{B}+d_{C} T_{C}\right]
$$

Where: I: current through the heated coil $(\mathrm{I}=0.25 \mathrm{~A}), \mathrm{V}$ : the potential difference at both ends of the heater coil $(\mathrm{V}=6 \mathrm{~V})$, and ds: specimen thickness. 


\section{RESULT AND DISCUSSION}

It is important to examine the immersion effect of polymeric materials in chemical solutions and water. In this paper, the unsaturated polyester resin was strengthened by using glass fibers, aluminum particles, and silica particles as a reinforced material with the percentages shown in Table 3. The influence of immersion in water on the coefficient of thermal conductivity was investigated, as well as the effect of immersion time in the water, acidic and basic solutions on the absorption percentage were studied. All treatments were performed by immersing the specimens at room temperature for periods of different times $(3,5,7,9,11$, and 13 weeks) for each solution.

\subsection{Effect of immersion time in the water on thermal conductivity}

Fig 1 displays the relationship between the values of thermal conductivity against the period of immersion of samples in water for a period of 3 to 13 weeks. It can be seen that the coefficient of thermal conductivity of $\mathrm{C} 2$ is greater than that of $\mathrm{C} 3$, which in turn is greater than that of $\mathrm{C} 1$, is because adding the fibers and aluminum in $\mathrm{C} 2$ raised the value of thermal conductivity of the composite, but the addition of silica particles and aluminum particles in $\mathrm{C} 3$ led to reducing it because the particles - usually - are porous, and when the material contains air spaces, it becomes less conductive because the gases are poor thermal conductivity. On the Other hand, when the immersion time increased, the coefficient of thermal conductivity decreased for all specimens, due to the spread of water through the interface region, cracks, and the weakly bonded areas, and this all reduces the binding forces. Moreover, when the immersion time increases, the degradation increases and thus leads to the failure of the material, as the water fills the existing voids and distances and thus act as a means of decomposition and disintegration.

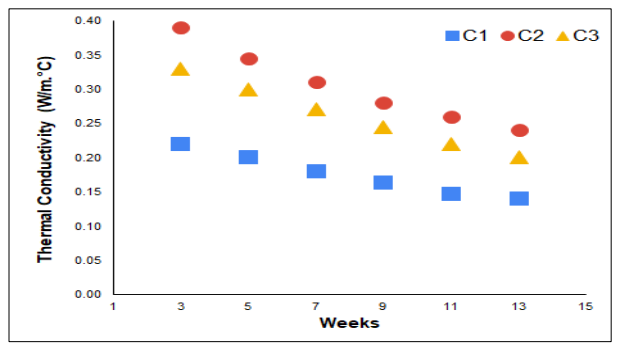

Fig. 1. Immersion time in the water on thermal conductivity.

\subsection{Effect of immersion time in the water on absorption percentage}

The process of absorption of all composite materials when exposed to moisture from the surrounding atmosphere or when immersed in water or chemical solutions follows Fick's law of the diffusion, meaning that the absorbed mass of water or solutions increases gradually and slowly with the square root of time until reaching a state saturation. The absorption by water or solution hurts the mechanical properties of composite materials because water and solutions weaken the bonds between the matrix and reinforcement materials.

Fig 2 shows the relationship between the absorption percentage for the three samples $\mathrm{C} 1, \mathrm{C} 2$, and $\mathrm{C} 3$ when immersed in water for 3 to 13 weeks at room temperature. It can be spotted that, the composite reinforced by aluminum particles and glass fibers has the greatest absorption 
percentage, followed by the composite reinforced by aluminum and silica particles, and then, to a lesser extent, the non-reinforced composite. The poor compatibility and bonding between the matrix and the fibers (whether synthetic or natural) is a major reason for increasing water absorption and weakening mechanical properties while the particles work to reduce pores and thus lead to reduced absorbency. It can be discovered that there was a slight increase in the absorbance value of all samples when immersed in water for 13 weeks.

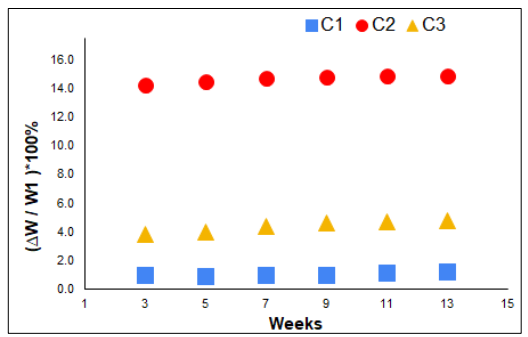

Fig. 2. Immersion time against absorption percentage (in water).

\subsection{Effect of immersion time in acidic and alkaline solution on absorption percentage}

Figs 3 and 4 show the relationship between the absorbance of the samples under investigation when immersed in an acidic solution $(\mathrm{HCl})$ and alkaline solution $(\mathrm{KOH})$ with normality $(1 \mathrm{~N})$ for $3,5,7,9,11$, and 13 weeks. During the first 3 weeks, it was evident that the absorption of sample $\mathrm{C} 2$ and $\mathrm{C} 3$ was approximately equal and much greater than that of sample $\mathrm{C} 1$, but as the submersion time increased, the absorbance of sample $\mathrm{C} 1$ increased while the absorbance of the other samples decreased. The containment of samples $\mathrm{C} 2$ and $\mathrm{C} 3$ on the discontinuous phase, including fibers, particles in addition to the presence of the interface leads to an increase in the penetration of the solution in them, and thus they reach saturation during the first three weeks, after that, a decrease in absorbance occurs based on the Fick's principle, furthermore, forming a coat from silica oxide that covering the specimen type 3 and operates as a protection layer and prevents from dissolving silica particles. Sample C1 contains continuous phase causes them to be slow to absorb solutions and thus their absorbance value increases with increasing the period of immersion. The specimens differ in the saturation event and that depends on various parameters such as the matrix model, the reinforced materials, the immersion period, and the volume fractions for reinforced materials.

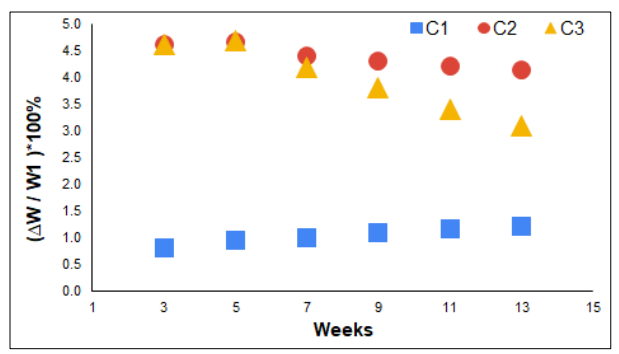

Fig. 3: Immersion time against absorption percentage (in acidic solution $(\mathrm{HCl})$ ). 


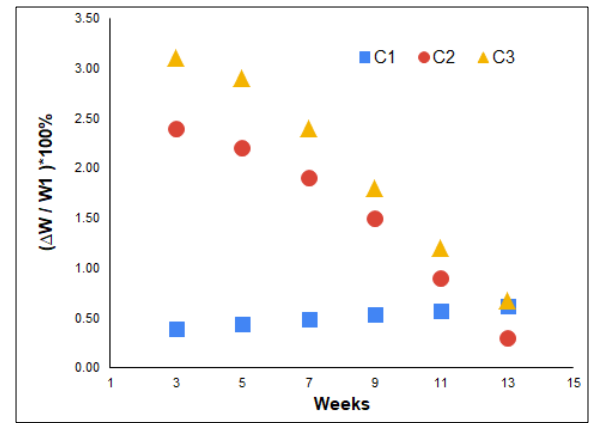

Fig. 4: Immersion time against absorption percentage (in alkaline solution $(\mathrm{KOH})$ ).

\subsection{Effect of reinforcement type in absorption percentage}

Figs 5, 6, and 7 show the relationship between the type of reinforcing material and the absorption percentage when samples are immersed in water, acidic and alkaline solutions for 3, 5, 7, 9, 11, and 13 weeks. An overview for all figures shows that the absorbance of composition material without reinforced is less than that the absorbance percentage when the composition material is reinforced with fibers or particles, especially when immersed in the alkaline solution, where the absorption rate does not exceed $0.6 \%$. On the other hand, the specimen of composition materials reinforced with aluminum particles and glass fibers has the highest absorbance that occurs (14.9\%) when immersed in water for 13 weeks. Furthermore, the absorption rate was decreased when increased the immersion period in the acidic and alkaline solution of the samples was fortified with fibers or reinforced with fibers and particles, while it increases for other cases. Increasing the immersion period in water leads to a large water penetration, which contributes to weakening the structure of the composite material thus the absorbance increases. Increasing the immersing period of the composite materials reinforced with fibers or particles in acidic or basic solutions leads to an increase in the digging of the surfaces of the fibers and particles, which increases the roughness of their surface and also increases their surface area, which increases the bonding strength and cohesion of them with the matrix material, This strengthens the composite structure and closes the voids and gaps, for this reason, the penetration of solution was reduced.

Over and above, C2 and C3 samples increased absorption suddenly after (3) weeks immersion in the acidic or alkaline solution, after that, it begins to drop. $\mathrm{C} 1$ samples suffered from deformation and obvious swells, but $\mathrm{C} 2$ and $\mathrm{C} 3$ it was less apparent. The microscopic pictures of the specimens that water immersion, $\mathrm{HCl}$, and $\mathrm{KOH}$ after 7 weeks are shown in Figure (8). We can notice the changes in the samples by comparing the specimen's pictures before and after immersion. 


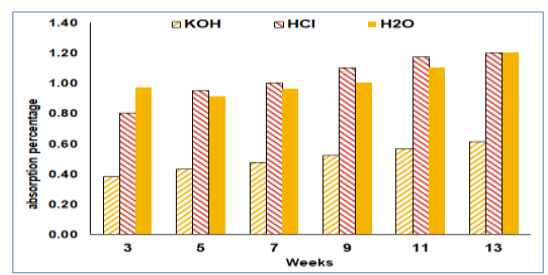

Fig. 5. Non-reinforced composite materials (C1) on absorption percentage.

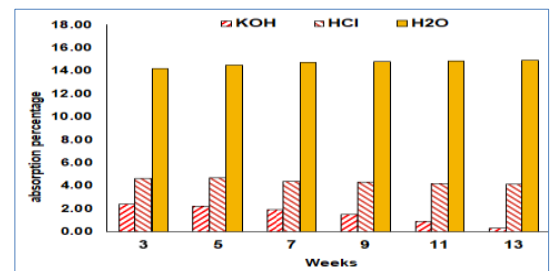

Fig. 6. Composite reinforced with aluminum particles and glass fibers (C2) on absorption percentage.

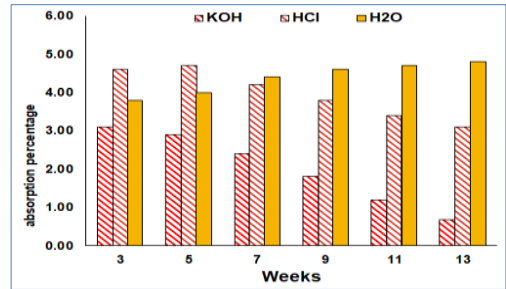

Fig. 7. Composite reinforced with aluminum particles and silica particles (C3) on absorption percentage.

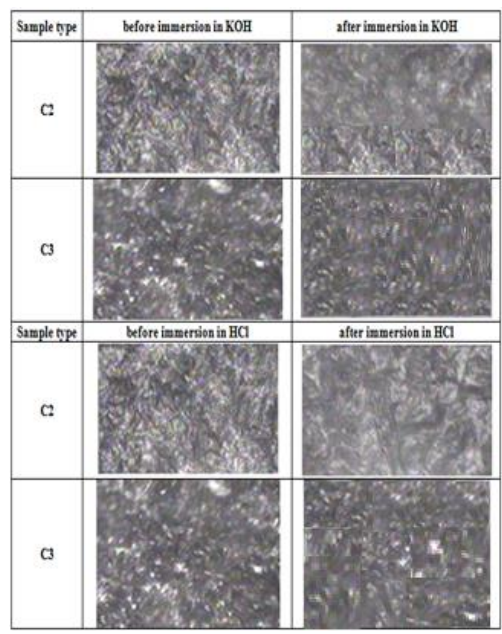

Fig. 8. Microscopic pictures (X10) for the samples before and after immersion in acidic and alkaline solution. 


\section{CONCLUSIONS}

Based on the results of practical experiments in the current research, it can be observed, the absorption was increased until it reaches the saturation state, after that, it begins to drop. The specimens differ in the saturation event and that depends on various parameters such as the matrix model, the reinforced materials, the immersion period, and the volume fractions for reinforced materials.

The values of the thermal conductivity coefficient decrease for all samples when increasing the immersion time, noting that the highest value of it is found in composite reinforced with aluminum particles and glass fibers. On the other hand, the absorption of the non-reinforced composites was lower than that of the reinforced composites. The highest percentage of absorption was obtained when composite materials reinforced with aluminum particles and glass fibers were immersed in water for 13 weeks. Furthermore, the absorption percentage of composites reinforced with fibers or particles was decreased with increasing the immersion period in the acidic and basic solutions, while it increases for non-reinforced samples.

Immersion of the composite reinforced with fibers or particles in acidic or basic solutions for a long time leads to increased drilling and roughness of the surfaces of the fibers and particles as well as, increases their surface area, bonding strength, and cohesion with the matrix material which leads to closes the gaps and reduces the solution penetration.

\section{ACKNOWLEDGEMENTS}

I extend my sincere thanks and appreciation to the technicians in the laboratories of the Technical Institute in Nasiriyah / Southern Technical University / Iraq for their assistance in completing this paper.

\section{REFERENCES}

[1] NAHAS M. N. (2005). New Development in Composite Materials - Recyclable and EnvironmentFriendly Composite Materials. Journal of King Abdulaziz University-Engineering Sciences. Vol. 16(1).

[2] Kalia S., \& Kaith B.S. (2009). Pretreatments of Natural Fibers and their Application as Reinforcing Material in Polymer Composites A Review. Polymer engineering and science/ Wiley. Vol. 49(7).

[3] Nabi D. S. , \& Jog J. P. (1999). Natural fiber polymer composites: A review. Advances in Polymer technology. Vol.18(4).

[4[ George J., Ivens J., \& Verpoest I. (2000). Mechanical properties of flax fiber reinforced epoxy composites. Die Angewandte Makromolekulare Chemie. Vol. 272(12).

[5] Rashed H., Islam M., \& Rizvi F. (2006). Effects of process parameters on tensile strength of Jute Fiber Reinforced Thermoplastic Composite. Journal of Naval Architecture and Marine Engineering. Vol.3(1).

[6] Khanam P. N. (2010). Sisal / carbon fiber reinforced hybrid Composites: tensile, flexural \& chemical resistance properties. Journal of polymer and the environment. Vol. 18(4).

[7] Ismail M. R., Ali A. M., \& Afify M. S. (2011). Mechanical Properties of Rice Straw Fiber-Reinforced Polymer Composites, Fibers and Polymers. Vol. 12(8). 
[8] Salem A., \& El-Tayeb N.S.M. (2014). The Impact of Rice Straw Microfibers Reinforced Epoxy Composite on Tensile Strength and Break Strain. International Journal of Scientific \& Engineering Research. Vol. 5(10).

[9] Mittal V., \& Sinha S. (2017). Effect of alkali treatment on the thermal properties of wheat straw fiber reinforced epoxy composites. Journal of Composite Materials. Vol. 51(3).

[10] Mittal V., \& Sinha S. (2018). Mechanical, thermal and water absorption properties of wheat straw/bagasse-reinforced epoxy blended composites. Advances in Polymer Technology. Vol. 37(7).

[11] Data Sheet (2020). Industrial chemicals \& resins Co. Ltd. Dammam, Saudi Arabia.

[12] Mallick P. K. (2007). Fiber Reinforced materials, Manufacturing and Design. 3rd Ed.

[13] Geodicke S., Kalleder A., Reinhard R., \& Schmidt S. (1999). Nano binders for Natural Composites, Book of Abstracts of NATO Advanced Research Workshop on Polymers and Composites for Special Applications, Poznan. Poland.

[14] Ahmed Sahib Mahdi, (2018), the effect of geometrical profile of direct extrusion die on the process efficiency using Visio plasticity method, Journal of Engineering and Applied Sciences, Vol. 14, No 13, pp, 11064-11067.

[15] Seymour R. B. (1990). Polymeric Composite. Alden Press. London.

[16] Krishna A. R., \& Krishna B. R. (2004). Thermal Analysis of Epoxy Based Fiber-Reinforced. IE (I) Journal - MC. Vol.84. 